\title{
INVESTIGATION OF RENAL ARTERY VARIATIONS WITH MULTIDETECTOR COMPUTED TOMOGRAPHY ANGIOGRAPHY TECHNIQUE
}

\author{
Gunes BOLATLI ${ }^{*}$, Mahinur ULUSOY KARDENIZ ${ }^{2}$, Mustafa KOPLAY ${ }^{3}$, Musa ACAR ${ }^{4}$, İsmail ZARASIZ ${ }^{5}$
}

${ }^{1}$ Siirt University, Faculty of Medicine, Department of Anatomy, 56100, Siirt, Turkey

${ }^{2}$ Akșehir Community Health Center, 42550, Konya, Turkey

${ }^{3}$ Selcuk University, Faculty of Medicine, Department of Radiology, 42250, Konya, Turkey

${ }^{4}$ Necmettin Erbakan University, School of Health Sciences, 42090, Konya, Turkey

${ }^{5}$ Girne American University, Faculty of Medicine, Department of Anatomy Department, 99320, Girne, NCTR

\begin{abstract}
It is necessary to have a comprehensive knowledge about renal vascular anatomy in order to be able to apply renal surgical procedures correctly. The renal artery is a pair to feed the right and left kidneys. Its variation is common. In this study, it was aimed to group the variations and to examine them clinically. Abdominal CT findings of 532 cases examined with MDCT device were included in the study. Variation was detected in 135 (25.3\%) of 532 cases. Of these variations, 95 (17.8\%) were early branching and 40 (7.5\%) were extra renal artery variations. The presence of renal artery variation may cause complications in surgical procedures such as kidney transplantation. Knowing the variations before the intervention to be made in the region will be guiding.
\end{abstract}

Keywords: Renal artery, Variations, Renal transplantation, Anatomy

*Corresponding author: Sirrt University, Faculty of Medicine, Department of Anatomy, 56100, Siirt, Turkey E mail: gunesbolatli83@gmail.com (G. BOLATLI)

Gunes BOLATLI $\quad$ (iD) https://orcid.org/0000-0002-7648-0237

Mahinur ULUSOY KARDENIZ (DD https://orcid.org/0000-0002-0647-8828

Mustafa KOPLAY (D) https://orcid.org/0000-0001-7513-4968

Musa ACAR (iD) https://orcid.org/0000-0002-5646-693X

İsmail ZARASIZ (iD) https://orcid.org/0000-0002-0551-337X

Cite as: Bolatlı G, Ulusoy Karadeniz M, Koplay M, Acar M, Zararsız İ. 2021. Investigation of renal artery variations with multidetector computed tomography angiography technique. BSJ Health Sci, 4(1): 22-25.

\section{Introduction}

It is important for surgeons to have a comprehensive knowledge of renal vascular anatomy when performing renal interventions. Procedures such as renal transplantation, laparoscopic and partial nephrectomy, urological and vascular surgery require a good knowledge of vascular anatomy and variations (Kumar et al., 2010; Urban et al., 2001).

The kidneys are fed by the renal artery (RA), which is separated from the aorta abdominalis at the lumbar 1-2 vertebra level. RA is a pair of an artery supplying the right and left kidneys. The artery of the right side is longer and higher. Gives 4-5 segmental branches before entering the kidneys (Cinar and Turkvatan, 2016; Urban et al., 2001), and variations of these branches are common (Kumar et al., 2010; Urban et al., 2001). The most common variations early separation of RA into segmental branches (early branching) and multiple RA (extra renal artery) (Kumar et al., 2010; Urban et al., 2001). The early branching variation of RA is divided into two as the hilar renal artery and polar renal artery according to the entrance place to the kidney (Kumar et al., 2010; Ozkan et al., 2006).

Extra renal artery (ERA) variation is also divided into accessory renal artery (hilar artery) and aberrant renal artery (polar artery) (Koc et al., 2007; Urban et al., 2001). The accessory renal artery (ARA) is the most common and clinically important variation of the RA. The accessory renal artery divides from the aorta or iliac artery as a separate branch, and its prevalence has been reported between $25 \%$ and $30 \%$ in different study groups (Cinar and Turkvatan, 2016; Kumar et al., 2010; Ozkan et al., 2006).

The presence of ARA is important in preoperative evaluation interventional procedures such as laparoscopic or retroperitoneoscopic nephrectomy for kidney transplantation, in patients with kidney tumors and nephron-sparing surgery. This evaluation will prevent possible surgical complications and renovascular hypertension due to isolated ARA stenosis (Aytac et al., 2003; Budovec et al., 2010; Koc et al., 2007; Ozkan et al., 2006; Ugurel et al., 2010).

Multidetector CT (MDCT) angiography is a fast, reliable, and non-invasive method that comprehensively evaluates vascular structures (Ahn et al., 2014; Holden et al., 2005). MDCT angiography is preferred for evaluating kidney donors. It has replaced traditional angiography in many institutions. The accuracy of MDCT angiography in 
the evaluation of renal vascular anatomy varies between 95\% and 100\% (Aytac et al., 2003; Budovec et al., 2010; Koc et al., 2007; Ozkan et al., 2006; Ugurel et al., 2010). Magnetic resonance angiography, another imaging method that allows non-invasive evaluation of renal vascular structures, remains in the background because it does not have a high spatial resolution as MDCT (Ramadan et al., 2011).

Kidney anomalies are among the most common organ anomalies, so the number of studies on RA is increasing. RA variations may be caused by the reason that the embryological development of the kidney is more complicated (Secen et al., 2014). Variations of RA have generally been done on healthy individuals. There is little variation study on cases such as kidney disease or hypertension patients (Secen et al., 2014). It is important to know whether the variations are associated with these diseases.

In this study, cases were grouped according to RA variations and examined clinically. The prevalence of cases with hypertension and kidney disease in cases with variations was evaluated.

\section{Material and Methods}

\subsection{Patient population}

Five hundred thirty-two cases who underwent abdominal CT examination with MDCT device for any reason were included in the study. Images were examined in terms of the presence of variation. As a result, the cases were divided into 3 groups.

1. Normal anatomy group (NA)

2. The Group with early branching variation (EB)

3. The group with an extra renal artery variation (ERA).

All groups were examined by gender. In addition, the rate of cases with hypertension and kidney disease in the variation groups was evaluated.

\subsection{Abbreviations}

$\mathrm{RA}=$ renal artery

$\mathrm{EB}=$ early branching variation

ERA= extra renal artery variation

HRA = hilar renal artery

PRA= polar renal artery

ARA = accessory renal artery

ABRA= aberrant renal artery

\subsection{MDCT protocol}

Axial CT images of the patients with a cross-section thickness of $3 \mathrm{~mm}$ were transferred to the workstation. Renal structures were evaluated morphometrically and morphologically on the axial, coronal, and sagittal plane images of these separated cases.

\subsection{Statistical analysis}

The data obtained in the study were analyzed using the SPSS (Statistical Package for Social Sciences for Windows 22.0) program. Number, percentage, mean and standard deviation were used as descriptive statistical methods in the evaluation of the data.

\subsection{Ethical Consideration}

This study was approved by the Mevlana University Faculty of Medicine Clinical Trials Ethical Committee. Approval date and number 12.03.2014 and 26857650/015.

\section{Results}

Variation was detected in 135 (25.3\%) of the 532 cases evaluated in our study ( 80 men, 55 women). 95 of these variations, $(17.8 \%)$ were $\mathrm{EB}$, and 40 of these variations (7.5\%) were ERA variations (Figure 1 ).

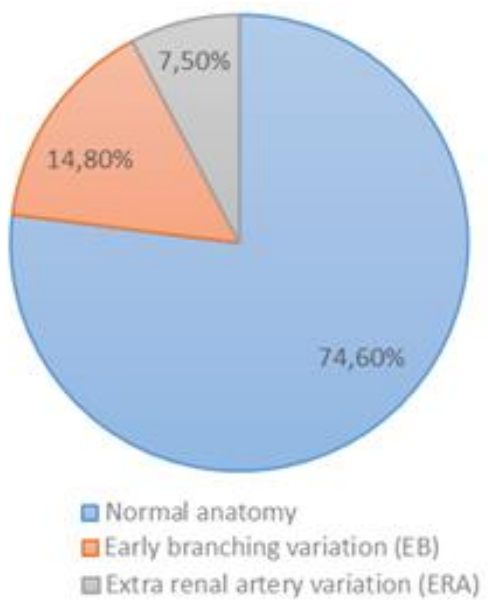

Figure 1. Incidence of variation.

Variation was observed in 95 cases, when we examine the EB variations (Figure 2). 80 of these cases (84.2\%) were bilateral, 15 of these cases $(15.8 \%)$ were unilateral early branching. 43 of the double-sided early branching variations were right and left hilar renal artery (HRA), 22 were right and left polar renal artery (PRA), 9 were right HRA left PRA, 6 were right PRA left HRA. Among the unilateral EB variations, right HRA was seen in 4 cases, right PRA in 1 case, left HRA in 5 cases, and left PRA in 5 cases. 41 of the 95 cases (43.1\%) were female, 54 (56.9\%) were male (Table 1 ).
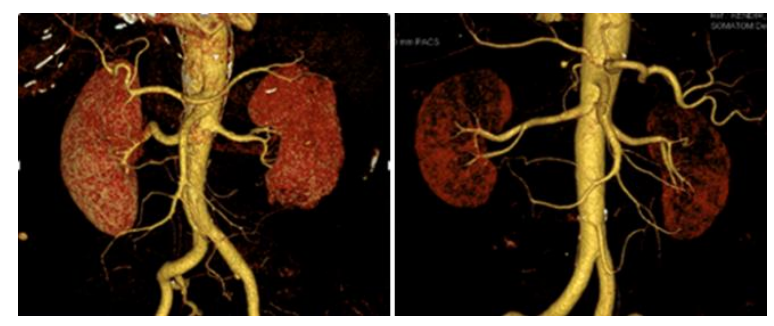

Figure 2. Early branching variation (EB).

29 of the 40 renal arteries with ERA variation (72.5\%) were bilateral variation, 11 were unilateral (27.5\%) variation (Figure 3). Right accessory renal artery (ARA) in 13 cases, right aberrant renal artery (ABRA) in 2 cases, left ARA in 10 cases, left ABRA in 4 cases, right and left ARA in 6 cases, right and left ABRA in 3 cases, right ABRA in 3 cases, left ARA in 2 cases detected. 15 of the 40 cases (37.5\%) were female, 25 (62.5\%) were male (Table 2). 
Black Sea Journal of Agriculture

Table 1. Early branching variations

\begin{tabular}{lcccccccccc}
\hline & \multicolumn{3}{c}{ Bilateral early branching } & \multicolumn{4}{c}{ Unilateral early branching } & Total \\
& R-L HRA & R-L PRA & RHRA-LPRA & RPRA-LHRA & RHRA & RPRA & LHRA & LPRA & \\
Female & 16 & 9 & 4 & 3 & 3 & 1 & 4 & 1 & 41 \\
Male & 27 & 13 & 5 & 3 & 1 & 0 & 1 & 4 & 54 \\
Total & 43 & 22 & 9 & 6 & 4 & 1 & 5 & 5 & 95 \\
& $8.1 \%$ & $4.2 \%$ & $1.7 \%$ & $1.1 \%$ & $0.7 \%$ & $0.2 \%$ & $0.9 \%$ & $0.9 \%$ & $17.8 \%$ \\
\hline
\end{tabular}

RHRA= right hilar renal artery, LHRA= left hilar renal artery, RPRA= right polar renal artery, LPRA= left polar renal artery

Table 2. Extra renal artery variations

\begin{tabular}{lcccccccc}
\hline & RARA & RABRA & LARA & LABRA & R-L ARA & R-L ABRA & RABRA-LARA & Total \\
Female & 2 & 0 & 3 & 4 & 2 & 3 & 0 & 1 \\
Male & 11 & 2 & 7 & 0 & 4 & 0 & 1 & 15 \\
Total & 13 & 2 & 10 & 4 & 6 & 3 & 2 & 25 \\
& $2.5 \%$ & $0.4 \%$ & $1.9 \%$ & $0.7 \%$ & $1.1 \%$ & $0.5 \%$ & $0.4 \%$ & 40 \\
\hline
\end{tabular}

RARA= right accessory renal artery, LARA= left accessory renal artery, RABRA= right aberrant renal artery, RABRA= left aberrant renal artery

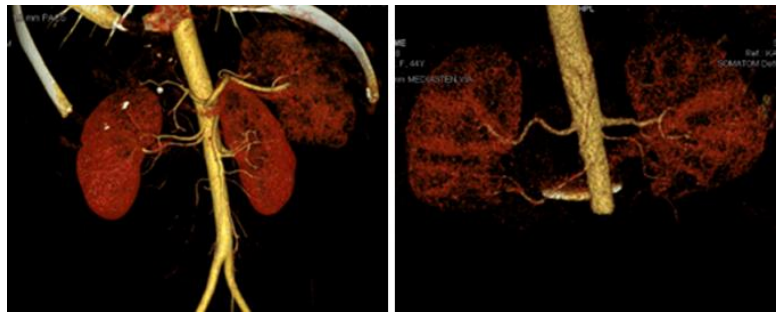

Figure 3. Early branching variation (ERA).

Patients with RA variations were also evaluated clinically. 11 of the cases with ERA variation (27.5\%) had hypertension, 5 (12.5\%) had kidney disease. In the cases with ED variation, 8 (8.4\%) were hypertension patients.

\section{Discussion}

Detecting RA variations has gained importance in terms of renal transplantations, interventional radiological procedures, urological and vascular surgery (Khamanarong et al., 2004). Especially before renal transplantation surgeries, the morphological structure of the kidney should be examined. Extra renal artery and early branching variations are of particular importance for the decision on the site of nephrectomy (Hanninen et al., 2005). RA variations are a significant risk for anastomotic and postoperative complications (Hung et al., 2012; Shoja et al., 2008; Vazquez et al., 2010).

Accessory renal artery (ARA) is the most common and clinically important variation of the renal artery. It divides from the aorta, or iliac artery as a separate branch, and its prevalence varies (Cinar and Turkvatan, 2016; Kumar et al., 2010; Ozkan et al., 2006; Urban et al., 2001). Bleeding that may occur as a result of an invasive procedure performed on it may result in open laparotomy, or the absence of ARA may cause renal infarction in the recipient and hypertension in the donor (Saba et al., 2008). Obtaining information about the presence or absence of an accessory renal artery does not eliminate the need for conventional CT or MR angiography before attempts such as nephron-sparing renal tumor surgery or kidney transplantation. However as this indirect information will show whether ARA is present, it may prevent additional investigations such as the search for isolated RA stenosis.

In the study conducted by Gümüş et al., RA variation was detected at a rate of $27 \%$. When we look at the ERA variation; they stated that $15.5 \%$ of the $\mathrm{EB}$ variation was on the right side (11\% ARA, 5.5\% ABRA), $16.5 \%$ were on the left side (12.6\% ARA, 3.9\% ABRA), $26.7 \%$ was on the right side, $16.6 \%$ was on the left side, $6 \%$ was on both sides, $24 \%$ was female cases, and $30 \%$ was male cases among all variations (Gumus et al., 2012).

Oner and Oner (2019) found 50\% of RA variation in their studies. $34.5 \%$ of these are 'ERA variation, $15.5 \%$ of these are EB variation. It is stated that $65 \%$ of the ERA variation is bilateral.

Ramadan et al. observed that one or more ARA were present at the rate of $22.8 \%$. It was observed that the kidneys with an accessory renal artery were unilateral at the rate of $19.8 \%$ and bilateral at the rate of $3 \%$ (Ramadan et al., 2011).

Cinar and Turkvatan (2016) reported a 31.9\% ERA variation. $11.5 \%$ of these were ar the right side $(2.6 \%$ ARA), $12.9 \%$ of these are at the left side (3.7\% ARA), $6.5 \%$ of these bilateral $(0.2 \%$ ARA) and there are $24.6 \%$ female cases and $32.3 \%$ male cases in the whole population.

In this study, It was found that RA variations are quite common $(25.3 \%)$, and the rate of variation in men is higher than in women. Our results are similar to the literature. On the contrary, it was determined that the incidence of $\mathrm{EB}$ variation was higher than the incidence of ERA variation. In addition, we made a comprehensive classification of RA variations, again different from the literature.

In some studies, it was stated that more than two ERAs were detected on the same side. (Bulic et al., 1996; Kuczera et al., 2009). This result was not found in our study.

Preoperative evaluation is important to evaluate renovascular hypertension, to prevent vascular 
reconstruction and abdominal aortic aneurysms (Hanninen et al., 2005). In a study conducted on hypertension patients, it was reported that there was $7.8 \%$ ERA (46.1\% left side, $45 \%$ left side, and $8.9 \%$ bilateral) (Secen et al., 2014). In another study, it was reported that there was $25.6 \%$ ERA (Kuczera et al., 2009). On the other hand, we found that $27.5 \%$ of the cases with ERA variation had hypertension, and $12.5 \%$ had kidney disease. In addition, 8.4\% of the cases with EB variation were hypertension patients. The number of studies examining hypertension and RA variation is limited according to the sources we can reach. Therefore, we think that the results will contribute to the literature. It has been stated that MDCT-Angiography is highly accurate in the diagnosis of RA variations compared to the conventional method (Gumus et al., 2012). It provides preliminary information to the radiologist, shortens the evaluation time, and speeds up the decision-making process (Aytac et al., 2003). We think that these variation rates, which we detected using the MDCT angiography method, may guide the evaluation of renal transplantation, essential hypertension, and kidney diseases.

\section{Limitations}

Our study was studied on a single race in a single hospital. The differences of the variations found according to the races could not be determined.

\section{Author Contributions}

BG; data collection or management, data analysis, manuscript writing, corresponding author. KUM; project development, consultant, manuscript editing. KM; data collection or management. AM; project development, $\mathrm{ZI}_{\text {; }}$ project development, manuscript editing.

\section{Conflict of Interest}

The authors declared that there is no conflict of interest.

\section{References}

Ahn SJ, Hong SH, Chai JW, Choi JY, Yoo HJ, Kim SH, Kang HS. 2014. Comparison of image quality of shoulder CT arthrography conducted Using $120 \mathrm{kVp}$ and $140 \mathrm{kVp}$ protocols. Korean J Radiol, 15(6): 739-745.

Aytac SK, Yigit H, Sancak T, Ozcan H. 2003. Correlation between the diameter of the main renal artery and the presence of an accessory renal artery - Sonographic and angiographic evaluation. J Ultrasound in Med, 22(5): 433-439.

Budovec JJ, Pollema M, Grogan M. 2010. Update on multidetector computed tomography angiography of the abdominal aorta. Radiol Clin North America, 48(2): 283-309.

Bulic K, Ivkic G, Pavic T. 1996. A case of duplicated right renal artery and triplicated left renal artery. Annals of AnatomyAnatomischer Anzeiger, 178(3): 281-283.

Cinar C, Turkvatan A. (2016). Prevalence of renal vascular variations: Evaluation with MDCT angiography. Diagnostic Intervent Imaging, 97(9): 891-897.

Gumus H, Bukte Y, Ozdemir E, Cetincakmak MG, Tekbas G, Ekici F, Uyar A. 2012. Variations of renal artery in 820 patients using 64-detector ct-angiography. Renal Failure, 34(3): 286290.

Hanninen E, Denecke T, Stelter L. 2005. Preoperative evaluation of living kidney donors using multirow detector computed tomography. Transpl Int, 18: 1134-1141.

Holden A, Smith A, Dukes P, Pilmore H, Yasutomi M. 2005. Assessment of 100 live potential renal donors for laparoscopic nephrectomy with multi-detector row helical CT. Radiology, 237(3): 973-980.

Hung CJ, Lin YJ, Chang SS, Chou TC, Lee PC. 2012. Kidney grafts with multiple renal arteries is no longer a relative contraindication with advance in surgical techniques of laparoscopic donor nephrectomy. Transplant Proc, 44(1): 3638.

Khamanarong K, Prachaney P, Utaravichien A, Tong-Un T, Sripaoraya K. 2004. Anatomy of renal arterial supply. Clinical Anat, 17(4): 334-336.

Koc Z, Ulusan S, Oguzkurt L. 2007. Association of left renal vein variations and pelvic varices in abdominal MDCT. Eur Radiol, 17(5): 1267-1274.

Kuczera P, Wloszczynska E, Adamczak M, Pencak P, Chudek J, Wiecek A. 2009. Frequency of renal artery stenosis and variants of renal vascularization in hypertensive patients: analysis of 1550 angiographies in one centre. J Hum Hypertens, 23(6): 396-401

Kumar S, Neyaz Z, Gupta A. 2010. The utility of 64 channel multidetector CT angiography for evaluating the renal vascular anatomy and possible variations: a pictorial essay. Korean J Radiol, 11(3): 346-354.

Oner S, Oner Z. 2019. Variations of Arteria renalis: a study of multidedector CT angiography. Kafkas J Med Sci, 9(1): 1-5.

Ozkan U, Oguzkurt L, Tercan F, Kizilkilic O, Koc Z, Koca N. 2006. Renal artery origins and variations: angiographic evaluation of 855 consecutive patients. Diagn Interv Radiol, 12(4): 183186.

Ramadan SU, Yigit H, Gokharman D, Tuncbilek I, Dolgun NA, Kosar P, Kosar U. 2011. Can renal dimensions and the main renal artery diameter indicate the presence of an accessory renal artery? A 64-slice CT study. Diagnostic and Interventional Radiol, 17(3): 266-271.

Saba L, Sanfilippo R, Montisci R, Conti M, Mallarini G. 2008. Accessory renal artery stenosis and hypertension: Are these correlated? Evaluation using multidetector-row computed tomographic angiography. Acta Radiologica, 49(3): 278-284.

Secen O, Akbulut M, Harman M, Yavcın O. 2014. Frequency of accessory renal artery in hypertensive patients. MN Cardiol, 21(3): 151

Shoja MM, Tubbs RS, Shakeri A, Loukas M, Ardalan MR, Khosroshahi HT, Oakes WJ. 2008. Peri-hilar branching patterns and morphologies of the renal artery: a review and anatomical study. Surg and Radiol Anat, 30(5): 375-382.

Ugurel MS, Battal B, Bozlar U, Nural MS, Tasar M, Ors F, Karademir I. 2010. Anatomical variations of hepatic arterial system, coeliac trunk and renal arteries: an analysis with multidetector CT angiography. British J Radiol, 83(992): 661667.

Urban BA, Ratner LE, Fishman EK. 2001. Three-dimensional volume-rendered CT angiography of the renal arteries and veins: Normal anatomy, variants, and clinical applications. Radiographics, 21(2): 373-386.

Vazquez R, Garcia L, Morales-Buenrostro L, Gabilondo B, Alberu J, Vilatoba M. 2010. Renal grafts with multiple arteries: a relative contraindication for a renal transplant? Transplant Proc, 42(6): 2369-2371. 